\title{
Effects of Vanadate on Vascular Smooth Muscles of WKY and SHRSP
}

\author{
Satoru Sunano, M.D., Tomoko Shimada, B.Pharm., \\ and Keiichi Shimamura, M.D.
}

Summary

The effects of vanadate on the vascular smooth muscle of Wistar Kyoto rats (WKY) and stroke prone spontaneously hypertensive rats (SHRSP) were examined. It was shown that sodium vanadate caused contraction of the aortae, mesenteric and basilar arteries of both strains, and that the reactivity was higher in SHRSP in the aorta and mesenteric artery. The vanadate-induced contractions were not blocked by 6 hydroxydopamine, adrenergic blocking agents, indomethacin or ouabain, while 4,4'-diisothiocyano-2,2'-disulfonic acid stilbene did. An increase in $\mathrm{K}^{+}$-concentration potentiated the vanadate-induced contractions of the mesenteric arteries and minimized the difference between preparations from WKY and SHRSP. In depolarized preparations incubated in KTyrode's solution ( $140 \mathrm{mM} \mathrm{KCl}$ ), vanadate induced phasic contractions followed by marked relaxation in the aortae of both species, the relaxation being more prominent in SHRSP aorta, while depolarized mesenteric arteries showed sustained contractions. It was revealed that vanadate caused contractions by acting inside the cell, and membrane permeability to vanadate might be higher in the vascular smooth muscle of SHRSP. The findings also suggested that vanadium, an inorganic element, can be involved in the initiation of hypertension in SHRSP when it acts on vascular smooth muscle.

\section{Additional Indexing Words:}

Blood vessels WKY SHRSP Contraction Sodium vanadate Sodium-potassium-ATPase Calcium-ATPase

\footnotetext{
$\mathrm{V}$ ANADIUM is a trace element present in animal tissues, and its pentavalent form, vanadate, is known to be a potent inhibitor of $\mathrm{Na}, \mathrm{K}$ ATPase and is thought to play a role in controlling various tissue activities. ${ }^{1)-3}$ The inhibition of $\mathrm{Na}, \mathrm{K}$-ATPase may lead to hypertension when it occurs in the cardiovascular system. It has been reported that vanadate elevated blood pressure in dogs when it was administered by infusion. ${ }^{4)}$ We have observed

From the Research Institute of Hypertension, Kinki University, Sayama, Osaka, Japan.

Address for reprint: Satoru Sunano, M.D., Research Institute of Hypertension, Kinki University, Ohno-higashi 377-2, Osaka-sayama, Osaka 589, Japan.

Received for publication August 18, 1986.

Manuscript revised February 16, 1987.
} 
that the infusion of vanadate also caused an elevation of blood pressure both in Wistar Kyoto rats (WKY) and in stroke prone spontaneously hypertensive rats (SHRSP), the effect being more prominent in the latter. ${ }^{5}$ ) Prolonged dietary administration of vanadate can also cause elevation of systolic blood pressure in rats. ${ }^{6)}$ Thus, the possibility that vanadate may play a role in the pathogenesis of hypertension has recently been presented. ${ }^{3)}$

Vanadate inhibits $\mathrm{Na}, \mathrm{K}$-ATPase present in vascular smooth muscle.7) It is also reported that vanadate induces contraction of various types of vascular smooth muscle, including the canine saphenous vein, ${ }^{81}$ guinea-pig aorta, ${ }^{91,10)}$ rabbit aorta ${ }^{10), 11)}$ and rat aorta. ${ }^{10,12)}$ Smaller arteries such as the basilar and mesenteric arteries of the rabbit, guinea-pig and rat also show a contractile response to vanadate, although, except for those of rabbit basilar artery, the responses are smaller when compared with those of aortae. ${ }^{10)}$ The contractile action of vanadate, however, has been explained by a mechanism other than the inhibition of $\mathrm{Na}$, K-ATPase.910) In any case, vanadate appears to elevate blood pressure by acting on vascular smooth muscle. In the present experiments, the effects of sodium vanadate on certain types of vascular smooth muscle of stroke prone spontaneously hypertensive rats (SHRSP) were studied and compared with those of the drug on similar preparations from normotensive rats (WKY).

\section{Materials and Methods}

Wistar-Kyoto rats (WKY) and stroke prone spontaneously hypertensive rats (SHRSP), aged 16 to 24 weeks, were used in the present experiments. The animals were killed by bleeding from the carotid artery under ether anesthesia. Aortae, basilar arteries and mesenteric arteries were dissected from both types of animals. Spiral cut preparations of vascular smooth muscle were made under a microscope, removing fat and connective tissue carefully. The endothelium of these preparations, however, was damaged during dissection of thin preparations.

The preparations were incubated in a modified Tyrode's solution of the following composition: $\mathrm{NaCl}, 137 \mathrm{mM} ; \mathrm{KCl}, 2.7 \mathrm{mM} ; \mathrm{CaCl}_{2}, 2.0 \mathrm{mM}$; $\mathrm{MgCl}_{2}, 1.0 \mathrm{mM} ; \mathrm{NaHCO}_{3}, 11.9 \mathrm{mM} ; \mathrm{NaH}_{2} \mathrm{PO}_{4}, 0.4 \mathrm{mM}$; glucose, $5.6 \mathrm{mM}$; equilibrated with a gas mixture of $95 \% \mathrm{O}_{2}$ and $5 \% \mathrm{CO}_{2}$ kept at $36^{\circ} \mathrm{C}(\mathrm{pH}$ 7.2). K-Tyrode's solution was made by replacing all $\mathrm{NaCl}$ in the modified Tyrode's solution with equimolar $\mathrm{KGl}$. The incubation media with an elevated- $K^{+}$concentration were made by mixing the modified Tyrode's solution and K-Tyrode's solution to obtain the desired $\mathrm{K}^{+}$-concentrations.

Tensions were measured isometrically by a force displacement trans- 
ducer (Shinkoh U-gage) and recorded by a thermal pen oscillograph (San-ei Sokki). The tensions induced by sodium vanadate were always compared with respective $\mathrm{K}$-induced contracture to normalize the contraction heights, and reported as relative tensions.

The noradrenaline content of arterial preparations was measured according to the method of Eriksson and Persson. ${ }^{13)}$ The preparations were weighed after being blotted with filter paper and homogenized in perchloric acid. The concentration of noradrenaline in the supernatant was assayed using high-performance liquid chromatography with electrochemical detection.

Sodium meta-vanadate was used in the present experiments, since it was difficult to determine the exact concentration because of the variations in water content of the drug. In addition, no marked difference could be observed in the action of sodium meta-vanadate and sodium ortho-vanadate (Sunano et al, unpublished observation). The other drugs used were: noradrenaline bitartrate (Sigma), phentolamine mesylate (Ciba), guanethidine sulfate (Tokyo Kasei), yohimbine hydrochloride (Wako), prazosin hydrochloride (Pfizer), 6-hydroxydopamine hydrochloride (Sigma), glutathione in reduced form (Wako), indomethacin (Wako), 4,4'-diisothiocyano-2,2'-disulfonic acid stilbene (DIDS, Wako) and ouabain (Sigma).

Statistical differences were determined using Student's t-test and a $p$ value smaller than 0.05 was considered to indicate statistical significance.

\section{Results}

1. Contraction of aortae and other arteries by sodium vanadate

Ages, body weights and blood pressures of animals used in the present experiments are summarized in Table I. The body weights of SHRSP were

Table I. Ages, Body Weights and Blood Pressures of Animals

\begin{tabular}{c|c|c|c}
\hline & & Range & Average \\
\hline Age (weeks) & WKY & $16-24$ & $20.6 \pm 0.7$ \\
& SHRSP & $16-24$ & $21.4 \pm 0.6$ \\
\hline Body weight (g) & WKY & $201-411$ & $285.8 \pm 11.1$ \\
& SHRSP & $200-350$ & $244.6 \pm 6.8^{*}$ \\
\hline $\begin{array}{c}\text { Systolic blood pressure } \\
\text { (mmHg) }\end{array}$ & WKY & $114-153$ & $131.1 \pm 2.1$ \\
& SHRSP & $179-278$ & $239.9 \pm 6.0^{*}$
\end{tabular}

Average values expressed as mean $\pm \mathrm{SE}(\mathrm{n}=30)$ in all cases. Asterisks indicate significant difference from those of WKY $(\mathrm{p}<0.001)$. 

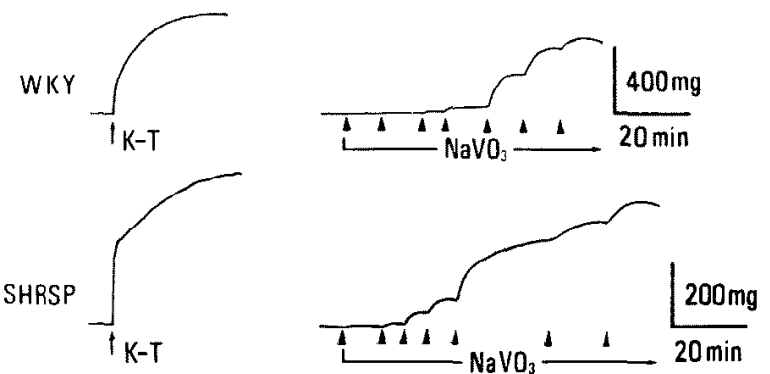

Fig. 1. Vanadate-induced contractions of aortae of WKY and SHRSP. $\mathrm{K}-\mathrm{T}$, the application of $\mathrm{K}-\mathrm{T}$ yrode's solution. Sodium vanadate $\left(\mathrm{NaVO}_{3}\right)$ was applied cumulatively at triangles $\left(5 \times 10^{-6}, 10^{-5}, 5 \times 10^{-5}, 10^{-4}, 5 \times 10^{-4}\right.$, $10^{-3}$ and $5 \times 10^{-3}$, from left to right, respectively).

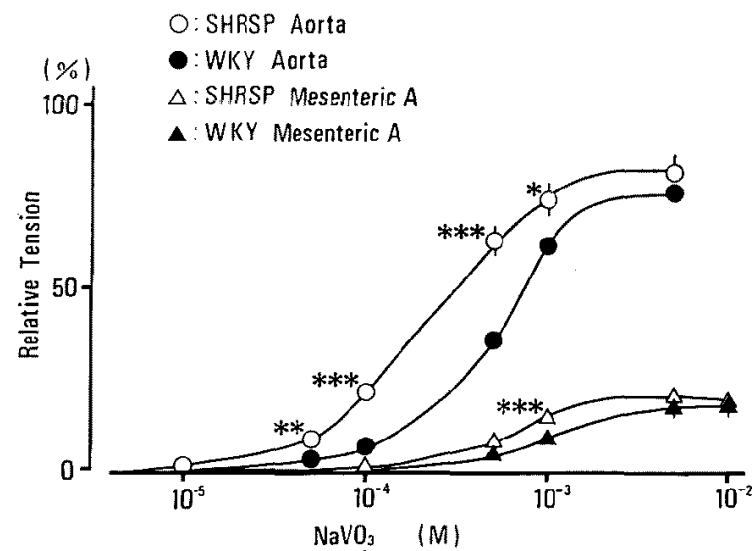

Fig. 2. Dose-response curve for sodium vanadate-induced contractions of aortae and mesenteric arteries. Heights of $\mathrm{K}$-induced contracture were taken as $100 \%$, and each contraction height was expressed as a percentage of this height. Asterisks indicate significant differences from respective preparations of WKY $(* 0.02<\mathrm{p}<0.05, * * 0.001<\mathrm{p}<0.01, * * * \mathrm{p}<0.001)$.

significantly smaller than those of age-matched WKY. The blood pressure of SHRSP was significantly higher than that of WKY; average systolic blood pressure was $131 \mathrm{mmHg}$ in WKY and $240 \mathrm{mmHg}$ in SHRSP.

Sodium vanadate induced sustained tension in the aortae of both WKY and SHRSP (Figs. 1 and 2). The threshold concentration for the development of tension was $10^{-5} \mathrm{M}$ in both WKY and SHRSP aortae. The $\mathrm{ED}_{50} \mathrm{~s}$ for vanadate-induced contraction of aortae of WKY and SHRSP obtained from individual dose-response curves were $5.1 \pm 0.39 \times 10^{-4} \mathrm{M}$ (mean $\pm \mathrm{SE}$, $\mathrm{n}=19)$ and $2.5 \pm 0.14 \times 10^{-4} \mathrm{M}($ mean $\pm \mathrm{SE}, \mathrm{n}=17)$, respectively, being significantly lower in the aortae of SHRSP $(p<0.001)$. The relative tensions developed in SHRSP aortae were significantly greater than those in WKY 
Table II. Numbers and Rates of Preparations Which Showed Spontaneous Contractions in the Presence of Sodium Vanadate

\begin{tabular}{l|l|c|c|c}
\hline \multicolumn{2}{c|}{ Type of blood vessel } & Preparation & $\begin{array}{c}\text { Spontaneous } \\
\text { contraction }\end{array}$ & Rate (\%) \\
\hline \multirow{2}{*}{ Aortae } & WKY & 62 & 22 & 35.5 \\
& SHRSP & 68 & 35 & $51.5^{*}$ \\
\hline \multirow{2}{*}{ Mesenteric arteries } & WKY & 38 & 0 & 0 \\
& SHRSP & 63 & 11 & $17.5^{* *}$ \\
\hline Basilar arteries & WKY & 6 & 2 & 33.3 \\
& SHRSP & 7 & 2 & 28.6
\end{tabular}

Sodium vanadate of $1 \mathrm{mM}$ was used. *, ** significantly higher than the preparations of WKY (* $0.01<\mathrm{p}<0.05, * * \mathrm{p}<0.01)$.

aortae at most concentrations (Fig. 2). The maximum tension was observed at $5 \times 10^{-3} \mathrm{M}$ in both $\mathrm{WKY}$ and SHRSP aortae: the heights of contraction in WKY and SHRSP aortae observed at this concentration were $76 \pm 2.2 \%$ (mean $\pm \mathrm{SE}, \mathrm{n}=15$ ) and $82 \pm 5.0 \%$ (mean $\pm \mathrm{SE}, \mathrm{n}=21$ ), respectively, of the heights of potassium induced contractions. Recovery after washout of the drug at this concentration, however, was extremely slow and it was often incomplete. The relative tensions induced by $10^{-3} \mathrm{M}$ sodium vanadate in WKY and SHRSP aortae were $62 \pm 2.5 \%($ mean \pm SE, $\mathrm{n}=17)$ and $74 \pm 4.3 \%$ $($ mean $\pm \mathrm{SE}, \mathrm{n}=21$ ) which were nearly their maxima $(\mathrm{p}<0.05)$.

In about half of the preparations, small spontaneous fluctuations of tension were observed in the presence of $1 \mathrm{mM}$ sodium vanadate (Table II). They often started after the tension had achieved their maxima. The frequency of occurrence of fluctuation of tension was higher in SHRSP aortae.

When sodium vanadate was used, at concentrations lower than $10^{-3} \mathrm{M}$, the developed tension fell to the initial level within 20 min after drug washout in the majority of preparations. In 7 of 47 preparations of WKY aortae $(14.9 \%)$ and 15 of 76 preparations of SHRSP aortae (19.7\%), however, the relaxations were followed by slow reelevation of the basal tension, and they were often associated with spontaneous fluctuations of tension. Twitch-like spontaneous contractions were also observed in 4 of 61 SHRSP preparations which showed complete relaxation and no elevation of the basal tension.

Sodium vanadate induced tension development in the mesenteric arteries as well, although the contraction heights were markedly lower than those of the aortae. Cumulative dose-response curves (Fig. 2) revealed that the maximum tensions were achieved at $5 \times 10^{-3} \mathrm{M}$ both in WKY and

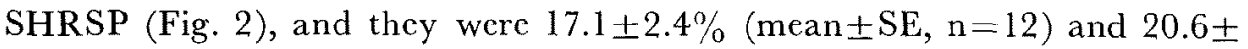
$1.0 \%$ (mean $\pm \mathrm{SE}, \mathrm{n}=7$ ), respectively. Recovery after washout of sodium 


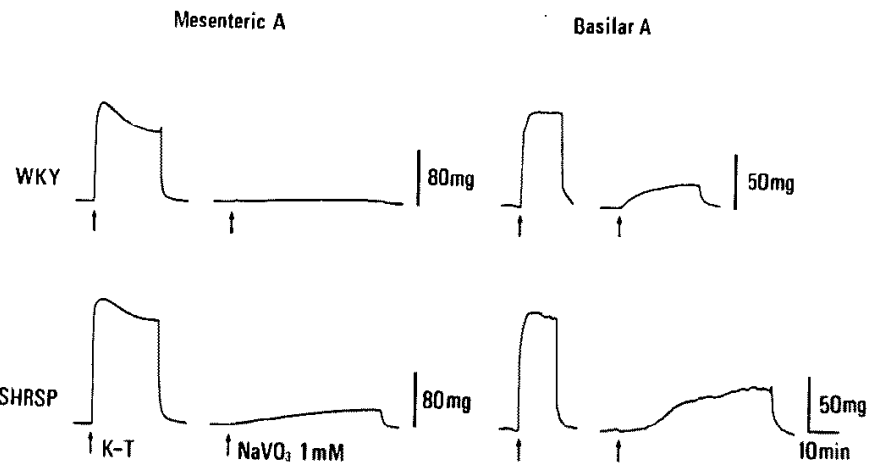

Fig. 3. Effects of sodium vanadate on mesenteric and basilar arteries. Vanadate $(1 \mathrm{mM})$ was applied after observing $\mathrm{K}$-induced contracture (K-T).

vanadate was also often incomplete when the concentration was higher than $5 \times 10^{-3} \mathrm{M}$. From these results and the results obtained in aortae, $10^{-3} \mathrm{M}$ vanadate was chosen to induce contractions in the following experiments.

Fig. 3 shows $1 \mathrm{mM}$ sodium vanadate-induced contractions in mesenteric and basilar arteries of WKY and SHRSP. $\mathrm{K}^{+}$-induced contractions of these arteries reached a maximum more rapidly than those of the aortae. One $\mathrm{mM}$ sodium vanadate induced only slight contraction in the WKY mesenteric arteries $\left(4.0 \pm 0.9 \%\right.$ of $\mathrm{K}^{+}$-induced contraction, mean $\pm \mathrm{SE}, \mathrm{n}=$ 10). The contractile responses of SHRSP mescnteric arteries to vanadate were also weak but significantly greater than those of the WKY mesenteric arteries, being $16.0 \pm 2.3 \%$ (mean $\pm \mathrm{SE}, \mathrm{n}=10$ ) of $\mathrm{K}$-induced contractions ( $<<0.001$, Fig. 4). In a certain number of preparations obtained from SHRSP, spontaneous fluctuation of tension was observed in the presence of $1 \mathrm{mM}$ sodium vanadate (Table II), whereas no such contraction was observed in similarly treated WKY mesenteric arteries. The actions of sodium vanadate at this concentration were reversible in mesenteric arteries, and immediate relaxation occurred following washout.

The contractile responses of basilar arteries of WKY and SHRSP to vanadate lay between those of the aortae and mesenteric arteries of the respective animals (Figs. 3 and 4). The fluctuation of tension was also initiated in certain preparations (Table II). Washing out sodium vanadate caused a rapid onset of relaxation in most of the preparations. However, in one fourth ( 3 of 12) of the preparations obtained from SHRSP basilar arteries, the relaxation was followed by slow reelevation of tension.

The heights of contraction induced by $1 \mathrm{mM}$ sodium vanadate in aortae, basilar arteries and mesenteric arteries of both types of animals are summarized in Fig. 4. The heights obtained by noncumulative application of 


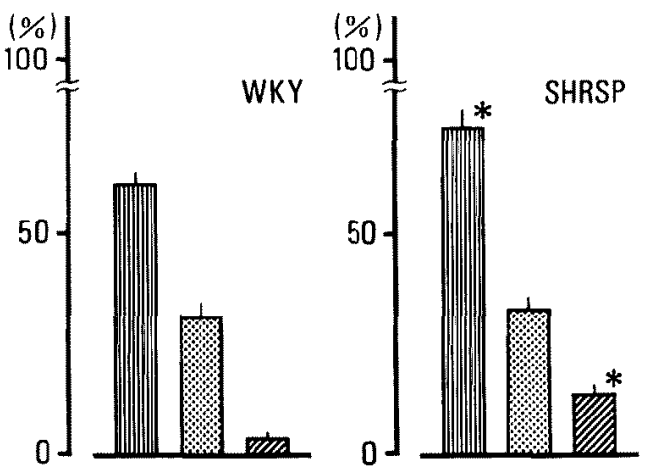

Aorta Basilar A

Mesenteric A

Fig. 4. Comparison of the heights of contraction by single dose $\left(10^{-3}\right.$ M) application of vanadate in various vascular smooth muscles. Each height of vanadate-induced contraction was expressed as a percentage of respective $\mathrm{K}$-induced contracture height. Vertical lines in the column express SEs. Number of experiments was 17,8 and 10, respectively, in aorta, basilar artery and mesenteric artery of WKY, and $21,13,10$, respectively, in aorta, basilar artery and mesenteric artery of SHRSP. Asterisks indicate significant differences from respective blood vessels $(p<0.05)$.

$1 \mathrm{mM}$ sodium vanadate were slightly lower than those obtained by cumulative application of the drug at the same concentration. As shown in this figure, the heights relative to those induced by potassium for aortae and mesenteric arteries were significantly higher in the preparations from SHRSP than those from WKY, while the difference was not significant in basilar arteries.

2. Comparative studies on the modes of action

To investigate the possible cause(s) of the difference in the response to vanadate of the preparations from WKY and SHRSP, some comparative experiments on the mode of action were performed.

In the first study, the involvement of intrinsic adrenergic nerves was examined by treating the preparations with 6-hydroxydopamine according to the method reported by Aprigliano and Hermsmeyer, ${ }^{14)}$ using superior mesenteric arteries. Although the treatment reduced the noradrenaline content from $1.91 \pm 0.143 \mathrm{ng} / \mathrm{mg}$ wet wt to an undetectable level below $0.005 \mathrm{ng} / \mathrm{mg}$ wet $\mathrm{wt}$, vanadate-induced contractions were not greatly influenced (Fig. 5). The sodium vanadate-induced contractions of arteries were not blocked by $5 \times 10^{-5} \mathrm{M}$ of phentolamine although $10^{-6} \mathrm{M}$ noradrenaline-induced contractions were completely abolished. Guanethidine 

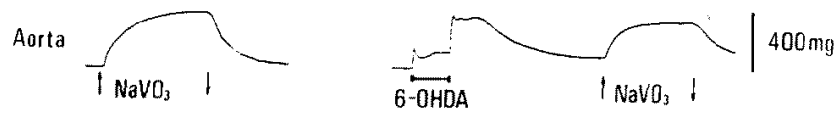

Mesenteric A
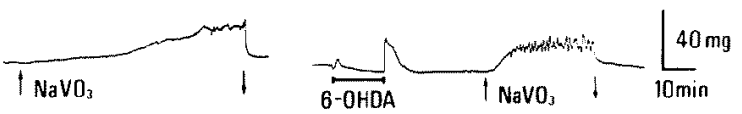

Fig. 5. Effects of 6-hydroxydopamine on vanadate-induced contraction of aorta and mesenteric artery of SHRSP. Preparations were treated with 6-hydroxydopamine (6-OHDA, $10^{-6} \mathrm{M}$ ) for the period indicated. Downward arrows indicate washing out with normal 'Tyrode's solution.

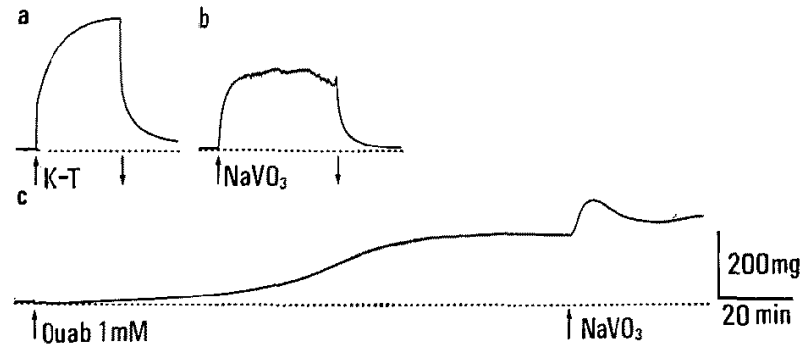

Fig. 6. Effects of treatment with ouabain on vanadate-induced contraction of WKY aorta. a, control $\mathrm{K}$-contracture. $\mathrm{b}$, control vanadate ( $1 \mathrm{mM}$ ) induced contraction. $c$, sodium vanadate was added $150 \mathrm{~min}$ after the application of I $\mathrm{mM}$ ouabain.

$\left(10^{-7} \mathrm{M}\right)$, yohimbine $\left(5 \times 10^{-7} \mathrm{M}\right)$ and prazosin $\left(10^{-6} \mathrm{M}\right)$ also did not block sodium vanadate-induced contractions. Moreover, treatment with indomethacin $\left(10^{-6} \mathrm{M}\right)$ did not affect the basal tension nor block the contractions induced by sodium vanadate (the results of these treatments are not shown in Figs.). Thus, no evidence of involvement of adrenergic transmission or prostaglandin in the initiation of contractions was demonstrated in either WKY or SHRSP arteries.

Fig. 6 shows the effects of ouabain on vanadate-induced contraction of a WKY aorta. Treatment with ouabain $\left(10^{-3} \mathrm{M}\right)$ caused slow tension development, which achieved its peak at about 2 hours after application. The application of $1 \mathrm{mM}$ sodium vanadate in the presence of ouabain caused a further increase in tension. The additional tension was smaller than that of the control, which might have been due to the elevation of basal tension by ouabain. However, the final tension developed in the presence of ouabain, and vanadate was slightly higher than the control vanadate-induced contraction in all preparations tested. Similar results were obtained in SHRSP aortae. Ouabain $\left(10^{-3} \mathrm{M}\right)$ failed to induce tension development in mesen- 

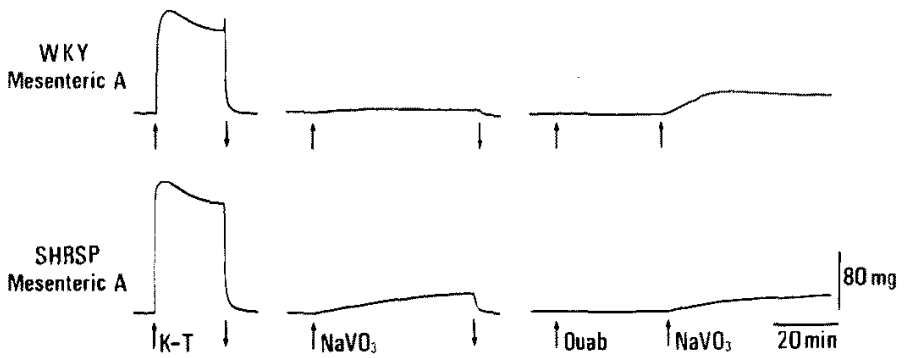

Fig. 7. Effects of ouabain on vanadate-induced contraction of mesenteric arteries of WKY and SHRSP. Sodium vanadate and ouabain concentrations were $1 \mathrm{mM}$. Downward arrows indicate washing out with normal Tyrode's solution.

A
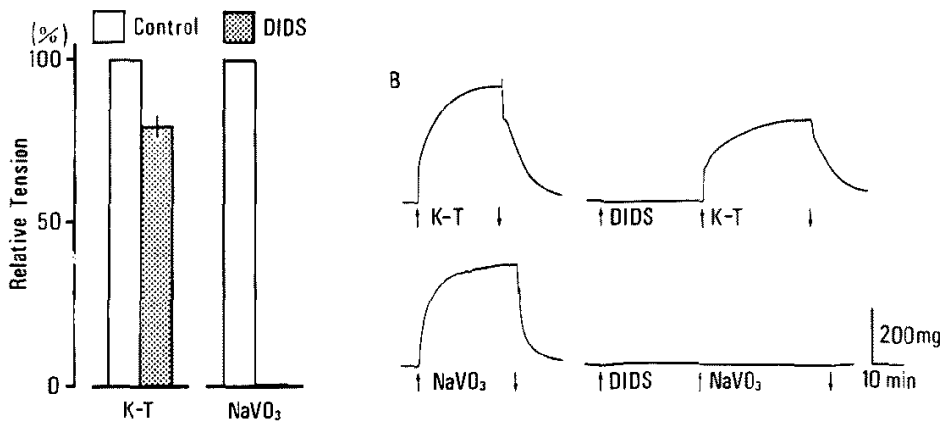

Fig. 8. Effects of DIDS on vanadate-induced contraction of SHRSP aorta. Vanadate of $10^{-3} \mathrm{M}$ and DIDS of $10^{-3} \mathrm{M}$ were used. In $\mathrm{A}$, control $\mathrm{K}$ - and vanadate-induced contractions were taken as $100 \%$, and the respective contraction heights in the presence of DIDS were expressed as a percentage of the control. In B, upward and downward arrows indicate the application of $\mathrm{K}$-Tyrode's solution (K-T) or sodium vanadate $\left(\mathrm{NaVO}_{3}\right)$ and washing out with normal Tyrode's solution, respectively.

teric arteries of WKY and induced only slight tension development $(7 \pm 1.4 \%$ of $\mathrm{K}$-induced contracture, mean $\pm \mathrm{SE}, \mathrm{n}=6$ ) in the preparations obtained from SHRSP when ouabain treatment was prolonged, as has previously been reported. ${ }^{15)}$ Sodium vanadate-induced contraction was not blocked by ouabain treatment, but rather, potentiated contraction was observed in certain preparations as shown in Fig. 7. Basilar arteries of both types of rats showed phasic contractile responses to the application of ouabain $\left(10^{-3} \mathrm{M}\right)$. The contractile response of the basilar arteries to sodium vanadate also was not blocked by ouabain (data not shown).

The effects of 4,4'-diisothiocyano-2,2'-disulfonic acid stilbene (DIDS), which has been shown to be an anion transport inhibitor, were also studied. 

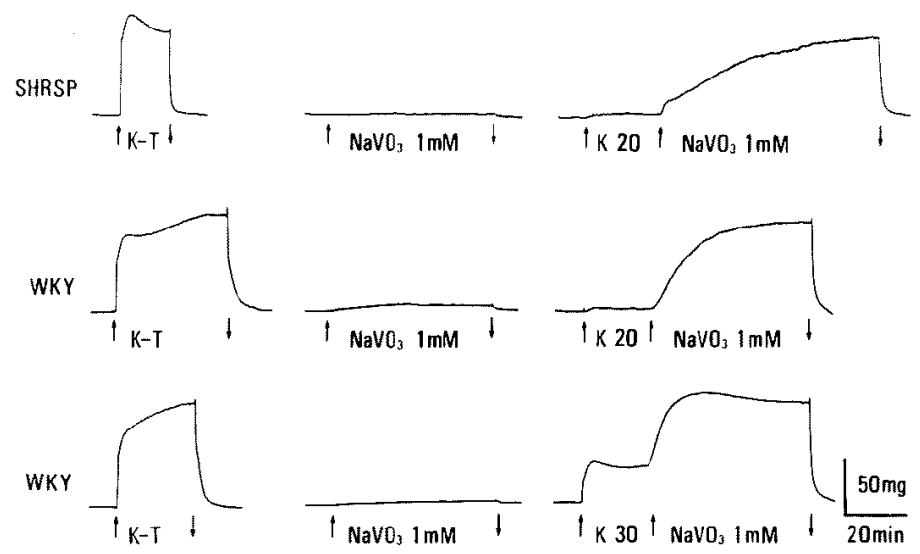

Fig. 9. Effects of increasing $\mathrm{K}$-concentration on vanadate-induced contraction of mesenteric arteries. Left, control K-induced contracture. Middle, control vanadate-induced contraction. Right, K-concentration was increased to 20 (K 20) or $30(\mathrm{~K} 30) \mathrm{mM}$, and then sodium vanadate was applied. Downward arrows indicate washing out with normal Tyrode's solution.

As shown in Fig. 8, DIDS at $10^{-3} \mathrm{M}$ completely blocked $1 \mathrm{mM}$ sodium vanadate-induced contractions in aortic preparations without changing the basal tension, while it depressed K-induced contracture of the same preparations only slightly. It should also be mentioned that vanadate-induced contractions were reproducible and could be induced repeatedly without a significant decrease in their heights.

Fig. 9 shows the effects of increasing $\mathrm{K}^{+}$concentration on sodium vanadate-induced contractions of mesenteric arteries of WKY and SHRSP. As described above, these preparations showed only a weak contractile response to sodium vanadate. Increase of $\mathrm{K}+$ concentration to $20 \mathrm{mM}$ caused no or only slight elevation of basal tension, but it potentiated sodium vanadateinduced contractions markedly. When $\mathrm{K}^{+}$concentration was elevated to $30 \mathrm{mM}$, a small and rapid elevation of basal tension followed by slow relaxation was observed. Sodium vanadate-induced contraction was enhanced more prominently, and tension development close to $\mathrm{K}$-induced tonic contraction was observed. Sodium vanadate could also induce tension development in depolarized preparations incubated in K-Tyrode's solution. The developed tension, however, was not as high as that observed in the presence of 20 or $30 \mathrm{mM} \mathrm{K}+$, which was presumably due to the elevation of basal tension by $\mathrm{K}^{+}$.

The effects of elevation of $\mathrm{K}^{+}$concentration on basal tension and on sodium vanadate-induced contractions of mesenteric arteries obtained from 


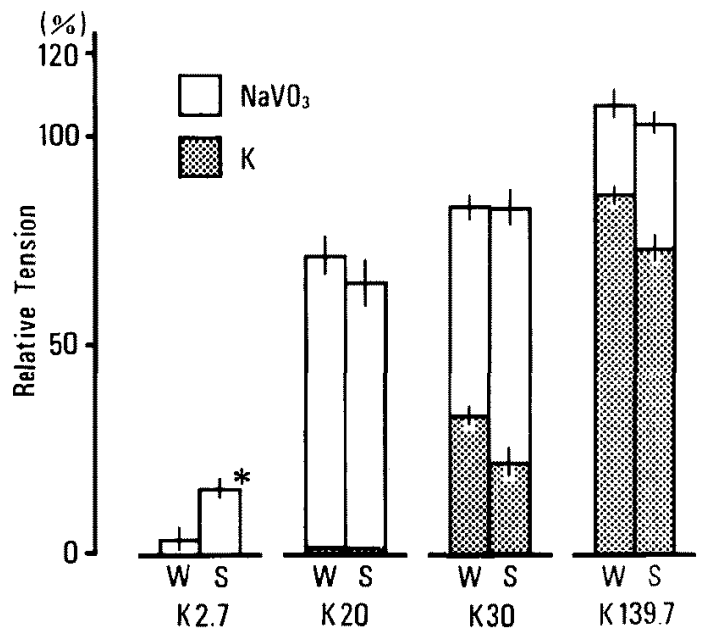

Fig. 10. Height of vanadate-induced contraction of mesenteric arteries of WKY and SHRSP in the presence of elevated-K+. The maximum heights of $\mathrm{K}$-induced contracture (phasic contraction heights) were taken as $100 \%$, and each height was expressed as a percentage of this height. Vertical lines in the columns express SEs ( $n=8$ to 16$)$. Stippled parts of columns represent the tension measured just before the application of sodium vanadate. W, WKY; S, SHRSP. K-concentrations are indicated at the bottom of the figure. Asterisks indicate significant difference from the value of WKY ( $p$ $<0.005)$. Note that $\mathrm{K}(139.7 \mathrm{mM})$-induced tensions are not $100 \%$, since maximum phasic contraction was taken as $100 \%$ and the tonic tensions at the point where sodium vanadate was applied were lower than this tension.

WKY and SHRSP are summarized in Fig. 10. In modified Tyrode's solution containing $2.7 \mathrm{mM} \mathrm{K}^{+}$, the contractile response of mesenteric arteries to sodium vanadate was significantly higher in the preparations from SHRSP, though the responses of blood vessels from both animals to the drug were weak. The contractile responses to sodium vanadate increased markedly in 20 and $30 \mathrm{mM} \mathrm{K}$, and the difference in the response between both animals became indistinct. The responses were, however, difficult to compare exactly, since the elevated- $\mathrm{K}$-induced elevation of basal tension was different.

When $1 \mathrm{mM}$ sodium vanadate was applied to depolarized aortae in $\mathrm{K}$-Tyrode's solution, relaxation was induced. 'The relaxation was preceded by a small phasic contraction (Fig. 11). The relaxation induced by sodium vanadate was significantly faster in the aortae of SHRSP than in that of WKY, though the final degree of relaxation was almost the same (Fig. 11).

The mesenteric arteries of both types of rats showed greater contractile response as described above, and only slight relaxation was observed, even at $60 \mathrm{~min}$ after the application of sodium vanadate (Fig. 11). There was no 

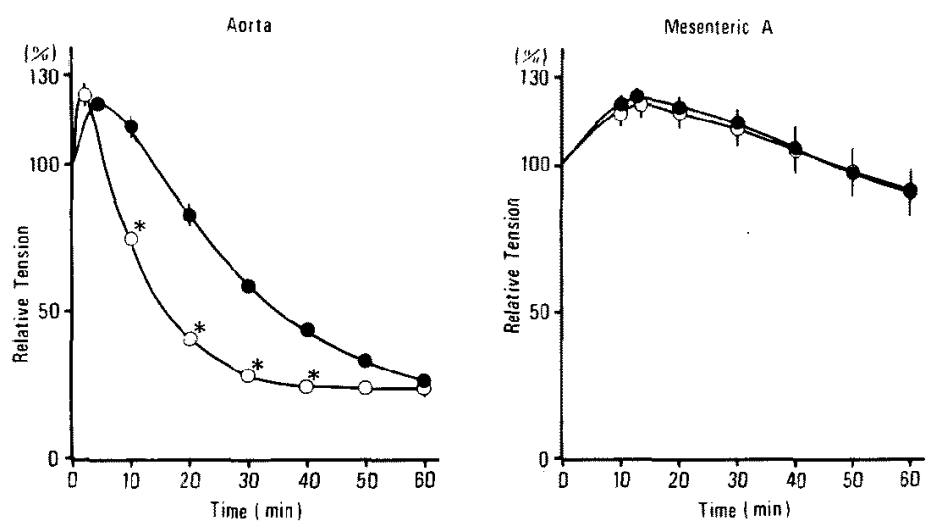

- WKY. O:SHRSP

Fig. 11. Time course of the effects of sodium vanadate on $\mathrm{K}$-depolarized preparations. K-induced tension measured just before the application of sadium vanadate $(1 \mathrm{mM})$ was taken as $100 \%$. Closed circles, WKY. Open circles, SHRSP. Asterisks indicate significant difference from the value of WKY $(\mathrm{p}<0.001)$.

significant difference in the responses of $\mathrm{K}$-depolarized mesenteric arteries obtained from WKY and SHRSP.

\section{Discussion}

Vanadium is widely distributed in animal tissues and is thought to play a role in controlling cell activities. It is also known that the pentaoxide form of vanadium, vanadate, has potent inhibitory action on $\mathrm{Na}, \mathrm{K}$-ATPase in cells of various tissues, ${ }^{1-3)}$ including vascular smooth muscle. ${ }^{73}$ The disturbance of $\mathrm{Na}, \mathrm{K}$-ATPase has been thought to be a cause of hypertension, especially when it occurs in vascular tissues. ${ }^{16)-19}$ In the present experiments, it was demonstrated that vanadate could induce contraction of vascular smooth muscle in both WKY and SHRSP, as has been reported for vascular smooth muscle of other animal species. ${ }^{\text {9)-12) }}$ Vascular smooth muscle of SHRSP was more sensitive to vanadate and showed higher contractile responses at all concentrations of vanadate. Several possible causes of the difference in the contractile response to vanadate can be considered. First, structural changes reported in spontaneously hypertensive rats, which may lead to changes in the contractile responses, should be taken into consideration (see Reference 17). In the present experiments, however, all contractile responses to vanadate are expressed as percentages of the heights of $\mathrm{K}$-induced contracture; therefore, the differences in vanadate-induced 
contraction may not be due to the structural changes in the vascular wall, especially the smooth muscle layer.

There have been a number of reports that sympathetic innervation of blood vessels is denser and, accordingly, the content and the release of noradrenaline are enhanced in SHR, when compared with those in WKY. ${ }^{20)-22)}$ We have also observed increased noradrenaline content and release in mesenteric arteries of SHRSP. ${ }^{23}$ The differences in intrinsic nerve activity can also be a cause of the difference, since it has been reported that the inhibition of $\mathrm{Na}, \mathrm{K}$-ATPase induces the release of a transmitter, ${ }^{24-28}$ ) and the release of noradrenaline by vanadate has also been proposed. ${ }^{11}$ However, the adrenergic blocking agents used in the present experiments did not block the contractile action of vanadate. Moreover, treatment with 6-hydroxydopamine failed to block the vanadate-induced contractions but rather potentiated them, though the treatment reduced the noradrenaline content of vascular preparations to an undetectable level. Thus, it appears that the adrenergic nerves are not involved in the initiation of contraction by vanadate; hence, the differences in the contractile response are not due to the difference in adrenergic innervation. Involvement of prostaglandins can also be excluded, since no changes in vanadate-induced contractions were observed following treatment with indomethacin.

It has been reported that $\mathrm{Na}$, K-pump activity of vascular smooth muscle is altered in spontaneously hypertensive rats (SHR) (see Reference 29). Ouabain-sensitive $\mathrm{K}$-activated phosphatase in the cell membrane of vascular smooth muscle, which reflects $\mathrm{Na}, \mathrm{K}$-ATPase content of the cell membrane, has been reported to be enhanced in SHR. ${ }^{30}$ ) This may be a way to compensate for an increased inward flux of sodium. The inhibition of $\mathrm{Na}, \mathrm{K}$-ATPase by vanadate reported in vascular smooth muscle, then, may cause the depolarization of smooth muscle membrane due to the inhibition of the electrogenic sodium pump or the retention of sodium; the former possibility might lead to contraction increasing membrane Ca permeability and the latter might also lead to contraction altering the $\mathrm{Na}-\mathrm{Ca}$ exchange mechanism (see Reference 16). However, it was shown in the experiments with ouabain that the contractile response of vascular smooth muscles of WKY and SHRSP to vanadate are not mediated by the inhibition of $\mathrm{Na}, \mathrm{K}$-ATPase. Ouabain at $10^{-3} \mathrm{M}$, which was used in the present experiments, has been thought to be sufficient to inhibit $\mathrm{Na}, \mathrm{K}$-ATPase of rat vascular smooth muscle almost completely ${ }^{31,32)}$ or by at least $75 \% .^{33)}$ We have recently observed that the mode of action is different in vanadate- and ouabain-induced contractions, especially in the involvement of intrinsic nerves and in the requircment of extracellular $\mathrm{Ca}^{15), 34)}$ Therefore, the difference in the con- 
tractile response to vanadate in WKY and SHRSP vascular smooth muscle cannot be explained by the difference in $\mathrm{Na}, \mathrm{K}$-ATPase activity of smooth muscle membrane.

The difference in membrane permeability to vanadate must be taken into consideration as a determinant factor of the action, ${ }^{35}$ ) since vanadate exerts its action inside the cell; thus, it has been demonstrated in a number of tissues that the effects of vanadate can be blocked by treatment with anion transport inhibitors. ${ }^{3,35), 36)}$ It has also been reported in other types of smooth muscle that vanadate-induced contractions were blocked by anion transport inhibitors such as 4-acetoamino, 4'-isothiocyano-2,2'-stilbene disulfonic acid (SITS) or DIDS, while $\mathrm{K}$-induced contracture and noradrenalineinduced contraction were not abolished.11,12,37) In the present experiments, DIDS completely blocked the vanadate-induced contraction of vascular smooth muscle of WKY and SHRSP, whereas it did not block K-induced contracture. It has also been shown that ouabain-induced contractions of corresponding preparations were not depressed by DIDS. ${ }^{15), 34}$ Although DIDS has been known to inhibit ATP-dependent Ca uptake of isolated plasma membrane vesicles of smooth muscle, ${ }^{38,39)}$ this cannot account for the action of DIDS observed in the present experiments, since the inhibition of Ca uptake of inside-out membrane vesicles should lead to an increase in tension rather than a depression. ${ }^{40)}$ Thus, it can be considered that vanadate penetrates the cell membrane and acts inside vascular smooth muscle cells of both WKY and SHRSP, as in other types of smooth muscle; therefore, the difference in membrane permeability to vanadate can be a cause of the difference in the contractile reaction. Similarly, the variation of the effects in various vascular smooth muscles can be explained by the variation of membrane permeability to vanadate, ${ }^{10)}$ although variation in other properties, such as difference in membrane excitability suggested by spontaneous tension fluctuation (Table II) and Ca handling described below, cannot be ruled out.

It is also reasonable to assume that moderate depolarization of the membrane by elevated- $K$ would increase the penetration of vanadate against the electrical gradient. This would thus potentiate vanadate-induced contractions, and would also lead to the elimination of the difference in the contractile response to vanadate of vascular smooth muscles of WKY and SHRSP. However, when intracellular vanadate reaches a much higher concentration, it inhibits the contractile reaction of actomyósin, as demonstrated in chemically skinned vascular smooth muscle.41),42) The accelerated relaxation by vanadate observed in SHRSP aorta depolarized in K-Tyrode solution may also be explained by the higher penetration of vanadate through 
the vascular smooth muscle membrane of SHRSP.

Vanadate induces contractions utilizing both extracellular and intracellularly bound $\mathrm{Ca} .{ }^{41)}$ In either case, the intracellular free Ca concentration is thought to be controlled by the Ca sequestering properties of membranous systems, which are known to be altered in SHR. ${ }^{29,43), 44)}$ Therefore, the differences in Ca handling in smooth muscles should also be taken into consideration as a cause of the differences in the response to vanadate in WKY and SHRSP vascular smooth muscle. However, no attempt was made to clarify this in the present study and it remains to be solved.

In conclusion, vascular smooth muscle of SHRSP showed a higher contractile response to vanadate than did that of WKY. The differences may be explained by the differences in the membrane penetration of vanadate and/or, presumably, by the differences in Ca handling during vanadateinduced contraction. The present results also suggest that vanadate can elevate blood pressure by acting on vascular smooth muscle to cause an increase in tension and/or potentiating tension development. The involvement of vanadate in the elevation of blood pressure might be greater in SHRSP as suggested by the higher reactivity to vanadate. And, experimentally, the infusion of vanadate has been shown to induce greater elevation of blood pressure in SHRSP,5) although a number of factors should also be taken into consideration for the action of vanadate on blood pressure.

\section{REFERENCES}

1. Simons TJB: Vanadate: a new tool for biologists. Nature 281 : 337, 1979

2. Macara IG: Vanadium: an element in search of a role. Trends in Biochem Sci 5: 92, 1980

3. Jandhyala IG, Hom GJ: Physiological and pharmacological properties of vanadium. Life Sciences 33: 1325, 1983

4. Inciarte JD, Steffen RP, Dobbins DE, Swindall BT, Johnston J, Haddy FJ : Cardiovascular effects of vanadate in the dog. Am J Physiol 239: H47, 1980

5. Shimada $\mathbf{T}$, Shimamura K, Yamamoto $\mathrm{K}$, Sunano $\mathrm{S}$ : The effects of ouabain and vanadate on vascular smooth muscles from SHRSP and WKY. Jpn Heart J 27: 555, 1986

6. Steffen RT, Parnnani MB, Clough DL, Huot SJ, Muldoon SM, Haddy FJ: Effects of prolonged dietary administration of vanadate on blood pressure in the rat. Hypertension 3 (suppl I): I-173, 1981

7. Searle BM, Higashino H, Khalil F, Bogden JD, Tokushige A, Tamura H, Kino M, Aviv A: Vanadate effect on the $\mathrm{Na}, \mathrm{K}$, ATPase and $\mathrm{Na}, \mathrm{K}$-pump in in vitro-grown rat vascular smooth muscle cells. Circ Res 53: 186, 1983

8. Huot S, Muldoon S, Pamnani M, Clough D, Haddy FJ : Effects of sodium vanadate ( $\mathrm{NaVO}_{3}$ ) on wall tension and $\mathrm{Na}^{+-} \mathrm{K}^{+}$pump activity in isolated canine saphenous vein. Fed Proc 38: 1036,1979

9. Ozaki $\mathrm{H}$, Urakawa $\mathrm{N}$ : Effects of vanadate on mechanical responses and $\mathrm{Na}-\mathrm{K}$ pump in vascular smooth muscle. Eur J Pharmacol 68: 339, 1980

10. Shimada T, Shimamura K, Sunano S: Effects of sodium vanadate on various types of vascular smooth muscles. Blood Vessels 23: 113,1986 
11. Hudgins PM, Bond G: Alteration by vanadate of contractility in vascular and intestinal smooth muscle preparations. Pharmacology 23: 156, 1981

12. Rapp JP: Aortic responses to vanadate: Independence from (Na, K)-ATPase and comparison of Dahl salt-sensitive and salt-resistant rats. Hypertension 3 (suppl I): I-168, 1981

13. Eriksson BM, Persson BA: Determination of catecholamines in rat heart tissue and plasma samples by liquid chromatography with electrochemical detection. J Ghromatography 228 : 143,1982

14. Aprigliano $\mathrm{O}$, Hermsmeyer $\mathrm{K}$ : In vitro denervation of portal vein and caudal artery of the rat. J Pharmacol Exp Ther 198: 568, 1976

15. Shimada T, Tsuji A, Shimamura K, Sunano S: Comparison of contractile effects of sodium vanadate and oubain in vascular smooth muscles of guinea-pigs and rats. Jpn J Smooth Muscle Res 22: 409, 1986

16. Blaustein M: Sodium ions, calcium ions, blood pressure regulation, and hypertension: a reassessment and hypothesis. Am J Physiol 232: C165, 1977

17. Folkow B: Physiological aspects of primary hypertension. Physiol Rev 62: 347, 1982

18. Beyer KG Jr, Peuler JD: Hypertension: Perspectives. Pharmacol Rev 34: 287, 1983

19. Doyle AE: Personal views on hypertension, in Hypertension, ed by Genest $\mathrm{J}$, Kuchel $\mathrm{O}$, Hamet P, McGraw-Hill, New York, p 659, 1983

20. Zsotér TT, Wolchinsky C, Lawrin M, Sirko S: Norepinephrine release in arteries of spontaneously hypertensive rats. Clin Exper Hyper Theory and Practice A4: 431, 1982

21. Head RJ, Cassis LA, Robinson RL, Westfall DP, Stitzel RE: Altered catecholamine contents in vascular and nonvascular tissues in genetically hypertensive rats. Blood Vessels 22: 196, 1985

22. Cassis LA, Stitzel RE, Head RJ: Hypernoradrenergic innervation of the caudal artery of the spontaneously hypertensive rat: An influence upon neuroeffector mechanisms. J Pharmacol Exp Ther 234: 792, 1985

23. Shimamura K, Shimada T, Yamamoto K, Sunano S, Okamoto K: Noradrenaline content and release in the mesenteric artery of SHRSP and newly established SHRSP (M-SHRSP). Blood Vessels (paper accepted for publication)

24. Tsuru $\mathbf{H}$, Shigei $T$ : Participation of catecholamine in the digitoxin-induced contraction of isolated dog veins. Jpn J Pharmacol 26: 120, 1976

25. Bonaccorsi A, Hermsmeyer $K$, Smith GB, Bohr DF: Norepinephrine release in isolated arteries induced by K-free solution. Am J Physiol 232: H140, 1977

26. Katsuragi $T$, Su C: Release of purine and noradrenaline by ouabain and potassium chloride from vascular adrenergic nerves. Br J Pharmacol 77: 625, 1982

27. Aarhus LL, Shepherd JT, Tyce GM, Verveuren TJ, Vanhoutte PM: Contraction of canine vascular smooth muscle cells caused by ouabain are due to release of norepinephrine from adrenergic nerve endings. Girc Res 52: 501, 1983

28. Vanhoutte PM, Verveuren TJ, Webb RC: Local modulation of the adrenergic neuroeffector interaction in the blood vessel wall. Physiol Rev 61: 151, 1981

29. Daniel EE: Role of altered vascular smooth muscle function in hypertension. in Vasodilatation, ed by Vanhoutte PM, Leusen I, Raven Press, New York, p 381, 1981

30. Wei J-W, Janis R, Daniel EE: Studies on subcellular fractions from mesenteric arteries of spontaneously hypertensive rats: Alterations in both calcium uptake and enzyme activities. Blood Vessels 13: 293, 1976

31. Aalkjær C, Mulvany MJ : Effect of ouabain on tone, membrane potential and sodium efflux compared with $\left[{ }^{3} \mathrm{H}\right]$ ouabain binding in rat resistance vessels. J Physiol 362: 215, 1985

32. Deth RG, Smart JL, Lynch CY, Walsh R: Lack of correlation between $\left[{ }^{3} \mathrm{H}\right]$ ouabain binding and Na,K-ATPase inhibition in rat aorta. Eur $\mathrm{J}$ Pharmacol 99: 45, 1984

33. Kwan CY, Grover AK, Daniel EE: On the ouabain-sensitive potassium activated p-nitrophenyl phosphatase activity of vascular muscle plasma membranes. Arch int Pharmacodyn 272: 245,1984 
34. Sunano S, Tsuji A, Shimada T, Shimamura K: Effects of vanadate and ouabain on various types of vascular smooth muscles. Jpn J Pharmacol 39 (suppl): $348 \mathrm{P}, 1985$

35. Grantham J: The renal sodium pump and vanadate. Am J Physiol 239: F97, 1980

36. Cantley LG Jr, Resh MD, Guidotti G: Vanadate inhibits the red cell Na,K-ATPase from the cytoplasmic side. Nature 272: 552, 1978

37. Ueda F, Urakawa $\mathrm{N}$ : Influence of DIDS on the dual actions of vanadate on high $\mathrm{K}$-induced contraction in the guinea-pig taenia coli. Jpn J Pharmacol 33: 894, 1983

38. Rangachari PK, Grover AK, Daniel EE: Effect of disulfonic stilbene on $\mathrm{Ca}^{2+}$ transport in smooth muscle plasma membranes. Can J Physiol Pharmacol 62: 1233, 1983

39. Grover AK, Kwan CY, Oakes PJ: Calcium pump, high-affinity Ca-ATPase, and other ATPase in dog antrum smooth muscle plasma mernbrane. Am J Physiol 248: C449, 1985

40. Daniel EE, Grover AK, Kwan CY: Isolation and properties of plasma membrane from smooth muscle. Fed Proc 41: 2898, 1982

41. Shimada T, Shimamura K, Sunano S: Involvement of extracellular calcium in the contractions of vascular smooth muscles induced by vanadate. Jpn J Pharmacol 39 (suppl): 348P, 1985

42. Peterson JW: Vanadate ion inhibits actomyosin interaction in chemically skinned vascular smooth muscle. Biochem Biophys Res Ciommun 95: 1846, 1980

43. Kwan CY, Daniel EE: Calcium transport by plasma membrane vesicle isolated from vascular smooth muscle of normal and hypertensive rats. in Vasodilatation, ed by Vanhoutte PM, Leusen I, Raven Press, New York, p 405, 1981

44. Kwan GY: Dysfunction of calcium handling by smooth muscle in hypertension. Can J Physiol Pharmacol 63: 366, 1985 